\title{
A modernidade de Voltaire: pensar 0 presente
}

\author{
Éliane Martin-Haag \\ martin.haag@wanadoo.fr \\ Université de Toulouse, Toulouse, França
}

resumo A ideia que avançamos aqui é que Voltaire é de pleno direito o inventor ou um dos inventores privilegiados do conceito de "tempos modernos" ou de uma nova atitude do filósofo face ao presente, compreendido como acontecimento no sentido de ruptura com "a craca e a ferrugem dos séculos" que ainda continuam a pesar sobre os espíritos. Segue-se este paradoxo: 0 acontecimento da modernidade é ao mesmo tempo um presente efetivo e um simples "crepúsculo" para o advento das Luzes.

palavras-chave Modernidade; Presente; Acontecimento; Costumes; Ilustração

Os filósofos que abordam Voltaire pela primeira vez ficam frequentemente perplexos: eles têm a impressão de estar diante de simples obras de circunstância ou de uma diluição da filosofia em seu contexto histórico-politico.Voltaire parece ser então um tipo de jornalista avant la lettre, ou de um polemista sem verdadeira consistência. No entanto, todos reconhecem o nascimento, no século das Luzes, de uma história não apenas como crônica dos acontecimentos, da qual Voltaire é particularmente representativo: tratar-se-á agora de procurar, por trás da proliferação empírica dos fatos, o evento em sentido forte, quer dizer, a mudança ou as mudanças que introduzem uma ruptura radical no "mundo moral" e que singularizam um tempo ou um período da humanidade. É por isso que já falamos de "jornalismo filosófico"1 em um autor que intervém no presente, por exemplo, no presente do célebre caso Calas, mas que presta testemunho por isso mesmo de um novo sentido do "presente" como conceito

Recebido em 07 de junho de 2012. Aceito em 05 de julho de 2012.

Traduzido por Rodrigo Brandão

doispontos, Curitiba, São Carlos, vol. 9, n. 3, p.13-28, dezembro, 2012 
filosófico: o caso Calas põe em jogo a própria história dos costumes e a tarefa das Luzes, a saber, a tarefa de sustentar a aparição de uma opinião pública que ousa enfim resistir aos poderes temporais da Igreja e de uma Magistratura corrompida, pensando por ela mesma, de maneira crítica, saindo daquilo que Kant chamará de condição de "minoridade".

A ideia que então avançamos aqui é que Voltaire é de pleno direito o inventor ou um dos inventores privilegiados do conceito de "tempos modernos" ou de uma nova atitude do filósofo face ao presente, compreendido como acontecimento no sentido de ruptura com "a craca e a ferrugem dos séculos" que ainda continuam a pesar sobre os espíritos. Segue-se este paradoxo: o acontecimento da modernidade é ao mesmo tempo um presente efetivo e um simples "crepúsculo" para o advento das Luzes. Aliás, está é a significação profunda que atribuímos a esse texto privilegiado das Singularidades da natureza: "Aquele que quisesse calcular os males da administração viciosa seria obrigado a fazer a história do gênero humano. Resulta de tudo isso que, se os homens se enganam em fisica, eles se enganam ainda mais em moral, e que somos destinados à ignorância e à infelicidade em uma vida que, tudo bem calculado, não tem mais do que três anos de sensações agradáveis. Mas quê! Responderia um homem prático, estávamos em melhor condição no tempo dos Godos, dos Unos, dos Vândalos, dos Francos e do Grande Cisma do Ocidente? Respondo dizendo que estávamos ainda pior. Mas digo que os homens hoje no comando dos governos sendo muito mais instruídos do que se era, é vergonhoso que a sociedade não tenha se aperfeiçoado em proporção das luzes adquiridas. Eu digo que essas luzes são apenas um crepúsculo"2.

Para sustentar a ideia de que as Luzes têm o estatuto paradoxal de um acontecimento real, mas ainda não efetuado, estudaremos como Voltaire fornece as condições de possibilidade deste novo pensamento do acontecimento presente.

\section{A possibilidade do acontecimento: uma concepção desconti- nuista da história}

Voltaire é célebre por sua luta contra o «otimismo» leibniziano. Ela põe em jogo a primeira condição para pensar o acontecimento, o rompimento 
com o princípio de continuidade que os leibnizianos transferiram do domínio da ontologia ou do tema da "cadeia dos seres" ao domínio histórico, com a ideia de uma "cadeia dos acontecimentos": os acontecimentos seriam aí tão inexorável e fatalmente ligados quanto se eles fossem os produtos de uma necessidade cega ou de uma ordem puramente fisica ou material.

Sublinhamos então que Voltaire reintroduz a contingência no universo, a fim de dar lugar à liberdade humana e a sua capacidade de produzir acontecimentos ou de romper com o peso de um passado de infelicidade e de servidão.

Voltaire começa então por estabelecer que Leibniz nega a liberdade de Deus, considerando que Deus escolhe o «melhor dos mundos possíveis", mas que esta escolha se realiza "necessariamente". Além disso, Leibniz sustenta também o tema da "cadeia dos seres". Após ter descrito a "gradação de seres que se eleva desde o mais leve átomo até o Ser supremo",Voltaire sugere que esta ontologia da continuidade não deixa de ter seu perigo, pois ela conduz a uma filosofia da história fatalista: "O presente partureja o futuro, diz-se. Os acontecimentos estão encadeados uns aos outros por uma fatalidade invencível; é o destino que, em Homero, é superior ao próprio Júpiter. Esse senhor dos deuses e dos homens declara que não pode impedir Sarpédon, seu filho, de morrer no tempo determinado" (VOLTAIRE, M. XVIII, 123). Ora, "esse sistema da necessidade e da fatalidade foi inventado em nossos dias por Leibniz, de acordo com o que se diz, sob o nome de "razão suficiente"; ele é no entanto muito antigo: não é de hoje que não há efeito sem causa, e que frequentemente a menor causa produz os maiores efeitos." (VOLTAIRE, M. XVIII, 123)

O fatalismo histórico supõe, portanto, uma temporalização da cadeia dos seres, mas também, e mais fundamentalmente, um uso abusivo do princípio de causalidade.

Por um lado, Voltaire reconhece que o Universo é um sistema ordenado, e que há, portanto uma cadeia espacial e temporal de causas e efeitos. É verdadeiro, por exemplo, que a morte de Sarpédon "dependia do rapto de Helena, e que este rapto estava necessariamente ligado ao casamento de Hécuba, que, remontando a outros acontecimentos, estava ligado à origem das coisas". Mas é falso dizer que "se um só desses fatos tivesse sido arranjado diferentemente, teria resultado outro universo", ou 
que "a menor das causas produz os maiores efeitos". Voltaire se opõe assim à racionalização da totalidade do real: ele recusa a consideração de todo o fato histórico como significante ou dotado de um alcance causal. Veremos a mesma coisa se considerarmos a ordem espacial do Universo. O estudo do clima nos obriga a admitir a noção estoica de causa distante. Todos sabem que o "vento que sopra do fundo da África e dos mares austrais traz parte da atmosfera africana, que cai como chuva nos vales dos Alpes" (VOLTAIRE, M. XVIII, 123). A causa e o efeito podem, portanto estar distantes um do outro, no tempo como no espaço. No entanto, não somos obrigados a reconhecer uma simpatia universal, ou uma cadeia contínua de causas e efeitos. É preciso distinguir a ordem e o destino: "Mas me parece que se abusa estranhamente da verdade desse princípio. Daí se conclui que não há sequer um pequeno átomo cujo movimento não tenha influenciado no arranjo atual do mundo inteiro; que não há sequer um pequeno acidente, seja entre os homens, seja entre os animais, que não seja um elo essencial da grande cadeia do destino" (VOLTAIRE, M. XVIII, 123).

O sofisma dos fatalistas consiste em tomar aquilo que é um "acidente" por um "elo essencial": a ordem inclui acontecimentos acidentais, que poderiam ou não ter lugar, sem que o conjunto do Universo fosse modificado. Trata-se de definir uma contingência que não destrói o princípio de causalidade, nem a afirmação da ordem e da Providencia divina. Assim, Voltaire estima que o princípio de causalidade significa que "todo efeito tem evidentemente sua causa", ou que nada se faz de nada, mas não se segue que toda causa tem seu efeito. É preciso representar o Universo não como uma cadeia continua de seres e acontecimentos, mas como as ramas de uma árvore genealógica, que compreende linhas apagadas, ou séries causais interrompidas: “Todos os acontecimentos são produzidos uns pelos outros, eu reconheço; se o passado partureja o presente, o presente partureja o futuro, todos têm pais, mas nem todos têm filhos. Aqui se passa a mesma coisa que em uma árvore genealógica: cada família remonta, como se sabe, a Adão, mas na família há muitos que morreram sem deixar posteridade." (VOLTAIRE, M. XVIII, 123-127).

O conceito de contingência ou de causa sem efeito ganha então variadas significações, de acordo com o caso ou o domínio considerado. Em primeiro lugar, é preciso reconhecer que existem fatos que são perfeitamente 
indiferentes à ordem do mundo. Essa contingência radical é ilustrada pelo exemplo de Magog, o grande ancestral dos russos: não tem importância, para os "assuntos presentes" dos russos, que Magog "tenha cuspido à direita ou à esquerda, próximo do Monte Cáucaso" (VOLTAIRE, M. XVIII, 123-127). A contingência reenvia a uma ausência de finalidade como à ausência de eficiência ou a uma contingência absoluta. Em segundo lugar, há uma contingência relativa que Voltaire estuda no artigo Clima. O clima é uma causa que não age em tudo, ou que não tem efeito em todos os domínios. Como Montesquieu, Voltaire afirma que, do ponto de vista do estudo dos costumes e das leis, o clima é uma causalidade contingente. As mudanças históricas têm lugar, mesmo que o clima permaneça estável. É assim que "Cícero zomba da Inglaterra", por causa de sua barbárie. Mas desde Cícero a Inglaterra se pôs a "produzir matemáticos", ainda que "o céu de Londres seja tão nebuloso quanto outrora”.

Daí Voltaire retira a existência de uma pluralidade de séries causais que tornam o futuro imprevisível: “Tudo muda no corpo e nos espíritos com o tempo. Talvez um dia os Americanos venham a ensinar as artes aos povos da Europa. O clima tem alguma força, o governo cem vezes mais, a religião unida ao governo ainda mais".

Voltaire chega assim a duas constatações. De um lado, existem séries causais que são independentes umas das outras: o clima não será jamais uma causa determinante para os costumes. De outro, há séries causais que podem se combinar, mas suas relações e sua importância respectiva variam com o passar do tempo. Aquilo que é causa segunda em um tempo se torna causa primeira em outro. O governo, por exemplo, é determinante para os costumes, se a religião não contrariá-lo. Voltaire articula assim a ideia de contingência e a de ordem: a ordem do mundo é infinitamente mais complicada do que imaginam os partidários da cadeia dos seres, e é esta própria ordem que engendra o encontro variável das séries causais (VOLTAIRE, M. XVIII, 199).

Em terceiro lugar,Voltaire introduz a contingência no coração mesmo da causalidade, afirmando que "todos têm pais, mas nem todos têm filhos". Isso significa que a causalidade em geral existe apenas virtualmente ou em potência. Não se pode deduzir a priori o efeito da causa: é apenas a posteriori, e depois do efeito, que reconhecemos a causa. Voltaire denuncia o sofisma que é inerente a todo pensamento fatalista: não se pode passar 
do conceito de causa à existência ou ao efeito, mesmo que a primeira causa seja divina ou material (VOLTAIRE, M. XVIII, 127).

Este reconhecimento da contingência esta destinado a operar uma reviravolta de valor em relação às teodicéias otimistas. De acordo com Voltaire, o Universo compreende uma assinatura divina, mas Deus se marca menos por uma presença positiva do que por uma ausência ou por uma negação. É quando a necessidade falha que a "mão invisível" (VOLTAIRE, M. XIX, 426) de Deus se revela. Tudo se passa então como se a contingência constituísse por si só o único traço da divindade e da finalidade. A experiência da contingência conduz à ideia de uma finalidade negativa. Deus não se revela por meio da continuidade dos acontecimentos, mas ao contrário, pelas falhas e rupturas que se introduzem na ordem a fim de dar lugar à liberdade humana. De agora em diante, o homem pode produzir acontecimento e romper com seu passado infeliz que não é mais uma fatalidade. Assim, é possível compreender o segundo aspecto do acontecimento, enquanto acontecimento presente das Luzes.

\section{Os costumes ou a ambivalência do presente: o presente é um problema e não uma aquisição}

Para mostrar que o pensamento do acontecimento não é somente efetivo, mas novo em Voltaire, é preciso de agora em diante estabelecer que ele não se inscreve numa filosofia ingênua do progresso, mas que ele constitui uma problema teórico-prático: pensar como este acontecimento, que é também um dever-ser, pode chegar a se efetuar, malgrado a inércia dos costumes que mudam apenas lentamente. Sobre esse ponto, a leitura de Montesquieu é essencial, pois este último soube redefinir o problema dos costumes, considerando-os como as causas sine qua non da eficácia e da duração ou, inversamente, da mudança das leis.

Comecemos por lembrar que Voltaire, autor do Ensaio sobre os costumes e do artigo "História" da Enciclopédia, retoma de Montesquieu a ideia de que um verdadeiro acontecimento é aquele que tem lugar na longa temporalidade dos costumes, e não simplesmente nesta ou naquela causa acidental, compreendida as causa políticas, pois as leis são impotentes para mudar os costumes ou o espírito de um povo (VOLTAIRE, VIII, 
223a). Para Montesquieu, os costumes têm, com efeito, o sentido de um constrangimento moral ou interior que o povo se impõe a si mesmo, em função de seu "espírito geral" ou de sua opinião, este espírito foi forjado pelas causas dominantes de sua história particular: clima, religião, máximas de governo, exemplos e "princípios" passionais tais como a honra nas monarquias moderadas ou a virtude igualitária nas antigas repúblicas ou democracias.

Como o filósofo, o legislador se vê assim confrontado com esta dificuldade. De um lado, ele não deve cair na "tirania da opinião" que se exerce quando se pretende mudar brutalmente os costumes seja pela força do despotismo, seja por uma desmesura da lei, que tem lugar quando a lei pretende se exercer sobre todas as coisas. De outro lado, ele também não deve simplesmente abandonar os costumes a eles mesmos, o que equivaleria a negar a possibilidade de todo aperfeiçoamento da humanidade. Sublinhemos enfim este ponto importante que, nas Luzes francesas, a precedência dos costumes e dos princípios passionais no homem agrava a dificuldade, que não se resolveria pela razão prática de Kant, enquanto aquela que pode expor publicamente os limites ao mesmo tempo legítimos e necessários de cada faculdade, mas também os limites do poder e da liberdade respectivos do cidadão e do Príncipe. Em outros termos, não se pode resolver o problema da efetivação do acontecimento das Luzes ou da liberdade de pensar pela definição dos limites de direito dessa liberdade, tanto no domínio teórico quanto no prático em sentido estrito. Neste último domínio, sabe-se que Kant estima que o cidadão pensa livremente, mas unicamente em uma esfera "pública" que é de fato uma esfera interior ou socialmente "privada", pois sua publicidade reenvia à presença em cada um de nos de uma razão moral que prescreve a máxima do pensamento ampliado ou a exigência de pensar de um ponto de vista universal. Fora daí e no exercício de sua profissão, o cidadão deve obedecer aos poderes, realizar sua função de pastor, de magistrado ou de soldado da maneira que os poderes lhe prescrevem. $\mathrm{O}$ cidadão de fato se encontra no domínio dos fins particulares que não derivam da razão (KANT, 1991, 45-49).

Em Voltaire, há sem dúvida, como em Kant, uma consciência moral indesarraigável em todo homem, pois ela vem de Deus, mas a história dos costumes se intercala ou se interpõe entre esta potência moral e sua 
passagem ao ato. Por isso o filósofo deve intervir na esfera pública no sentido da esfera política e social, e isso definindo suas possibilidades de ação e os limites dessas possibilidades pelo estudo histórico-filosófico dos costumes. Dito de outra maneira, o filósofo estuda o estado dos costumes, por exemplo, os progressos sempre limitados da tolerância tanto política quanto religiosa, para daí tirar a definição "daquilo que se pode fazer e daquilo que não se faz". Isso significa ainda que Voltaire se vale da própria fragilidade do acontecimento, ou da ambivalência dos costumes sempre divididos entre o antigo e o moderno, para tentar reformar esses costumes, sem se chocar com eles por meio da tirania da opinião.

É a esta perspectiva que se deve remeter o modo de intervenção de Voltaire nos grandes acontecimentos de seu tempo. Trata-se notadamente de pôr os homens em face de suas contradições, tanto na opinião quanto na ação, pois essas contradições dão testemunho de uma "inconsequência" generalizada dos costumes. Essas inconsequências na verdade refletem a luta dos poderes tradicionais da Igreja e das Monarquias mais ou menos despóticas contra o acontecimento de uma nova liberdade de pensamento. Por isso Voltaire sublinha "que há por toda parte usos em contradição com as leis", pois “os homens são em toda parte igualmente loucos; fizeram leis por circunstância, como reparamos brechas numa muralha”. Na Europa em particular, "tudo foi feito como a roupa de Arlequim": "emprestou-se do passado velhos farrapos de todas as cores" e "Arlequim ficou ridículo, mas foi vestido" (VOLTAIRE, M. XVIII, 251-256). A prática militante de Voltaire consiste então em se servir dessas contradições para reativar e sustentar as forças de resistência aos poderes arbitrários, forças que sempre existiram, mesmo no estado de minoridade, caso contrário, a história apresentaria apenas o quadro único da infelicidade e da maldade humana e não o quadro de uma multiplicidade de inconsequências. No entanto, e este ponto é essencial, os costumes sofrem uma crítica que deve ser adaptada às relações de forças presentes que eles exprimem, pela dupla participação do passado e das novas Luzes.

Em nossa obra anterior (MARTIN-HAAG, 2002), examinamos em particular o caso exemplar dos Calas, pois ele permite colocar o Parlamento e a magistratura perante suas inconsequências, que consistem em se apresentarem ao mesmo tempo como os defensores tradicionais do povo ou do Terceiro estado e se submeterem a um fanatismo 
religioso que pretendiam ter superado. A honra dos magistrados é desse modo posta em perigo: a vergonha de perder a honra deve incitar à aliança com as forças do presente.Voltaire retoma então a ideia segundo a qual é pelos costumes e pelas paixões que chegamos a operar uma mudança estrutural nos governos e nas leis, mas tendo a originalidade radical de justificar esta afirmação por um pensamento do presente como sempre constituído de relações de forças contraditórias. Os cidadãos são assim incitados a realizar o presente em seus costumes, costumes que são os motores de suas ações ou inversamente os responsáveis por sua passividade. A dificuldade de reformar os costumes é assim tratada por uma prática-teórica que não tem nunca limites necessários e definitivos, mas os limites sempre fluídos dos movimentos da opinião, movimentos que a vigilância do filósofo não cessa de escrutar, para daí tirar o sentido essencial que consiste na sua relação como o acontecimento ou com a novidade radical das Luzes.

A partir disso, esta nova prudência não consiste somente na historicização dos tratados cartesianos das paixões. É verdade que, como já sublinhamos, Voltaire reinventa o célebre remédio do "antidotismo" que opõe uma paixão ao seu contrário: ele opõe uma paixão passiva ou herdada do passado à paixão ativa e presente de trabalhar para a efetivação das Luzes (MARTIN-HAAG, 2002, 132-135 e 139-140). Assim podemos afirmar que a questão, ainda mais fundamental, é expandir ao povo ou maior número possível de pessoas a nova atitude filosófica que consiste em refletir sobre sua relação com o acontecimento presente, de modo a aceder a uma consciência histórica de si e de seu papel na cidade. A criação de um espaço público de discussão ou de uma opinião pública interessada pelas questões jurídicas, econômicas e políticas, deve agora se efetuar na cidade e não simplesmente em uma interioridade do tipo kantiana. $\mathrm{O}$ modelo inglês, da maneira tal que Voltaire o faz operar, vem provar a possibilidade desse acontecimento das Luzes como processo ou passagem aos tempos modernos. A seus olhos a Inglaterra já passou das simples exortações francesas aos Reis a uma verdadeira liberdade de pensar, de escrever e de se exprimir. É assim "que havia oitocentas pessoas em Londres que tinham o direito de falar publicamente e sustentar os interesses da nação" ou de decidir por todos, agora "cinco ou seis mil pretendem a mesma honra", enquanto que "o resto se erige em juiz de todos eles". Cada um está então 
autorizado a imprimir o que pensa das questões públicas, e toda a nação "se encontra na necessidade de se instruir" (VOLTAIRE, M. XXII, 163) a respeito dos debates presentes.

Reconhece-se que o estatuto do filósofo se encontra transformado: ele não é mais um rei legítimo, nem o representante das classes médias esclarecidas, mesmo que esta situação possa lhe ter sido imposta de fato, mas, de direito, trata-se de transmitir ao conjunto do povo uma nova atitude de modernidade e uma nova consciência histórica de si, a fim de fazer passar o maior número do estado de "populaça" ao estado republicano de povo. O objetivo de Voltaire é mais precisamente criar uma verdadeira sociedade entre todos os membros da cidade: os debates e a liberdade de comunicar permitiriam instaurar um verdadeiro laço social, refletido e livremente consentido.

Entretanto,Voltaire, como todos sabem, não é nem um pouco otimista quanto à possibilidade de pôr fim nas lutas contra os poderes temporais. O povo de fato permanece amplamente no estado de "populaça" ignara e fanática e nem os Príncipes e a Igreja nem os parlamentos estão prontos a abandonar seus privilégios. O peso do passado e dos costumes que engendrou é tal que Voltaire aconselha, repetidas vezes, a aproveitar os tempos presentes, pois “talvez, eles serão curtos" (VOLTAIRE, M. XXX, 586).

Assim, não há termo ou fim da história tal qual Voltaire a concebe, isto é, como uma luta perpétua contra a inércia dos costumes passados. $\mathrm{O}$ presente das Luzes revela assim uma nova forma de filosofia "perene": a necessidade perpétua de lutar contra poderes que podem mudar de natureza, mas que serão sempre os defensores da sujeição da maioria. O pensamento do presente também se confirma singular em um segundo sentido em Voltaire: ele tende a transformar a filosofia em uma filosofia social que deve ser capaz de renovar suas forças e suas formas críticas para estar apta para se medir com as formas de sujeição futuras. A máxima das Luzes se reformula então como uma exigência de pensar livremente, mas também de sempre repensar o presente que pode ser uma causa sem efeito ou um emaranhamento de causas prenhes de efeitos imprevisíveis. Voltaire nos deixa então esta interrogação: as Luzes existem? E se não, como trabalhar para a sua efetivação futura? 


\section{0 principal obstáculo ao acontecimento das Luzes: a "popula- ça" ou o problema social}

No domínio teórico, Voltaire põe fim à era dos gênios ou do pensador solitário e despótico que apresenta seu sistema como o único verdadeiro e de uma verdade tão absoluta quanto o poder político do déspota (MARTIN-HAAG, 2002, 17-29). O acontecimento das Luzes é então apresentado como a aparição de um pensamento livre e crítico que destitui a autoridade dos autores e das Escolas. Aqui, é preciso estabelecer que o mesmo processo tem lugar no domínio teórico-prático.

Notemos de início que a Enciclopédia traz um artigo "Social" em que se afirma se tratar de uma palavra nova, reveladora, portanto, de uma nova dimensão da existência humana (Enciclopédia, t. XV, 251b). A importância adquirida pela noção de costumes já nos lança na perspectiva desta dimensão, pois os costumes constituem o próprio laço social, ou os valores partilhados e postos em prática por todos.

Voltaire é parte ativa desse acontecimento da consciência social, de início pela sua redefinição da virtude que coincide com os costumes enquanto laço social. A sociedade é natural, e desejada por um Deus que nos deu "um horror invencível por tudo aquilo que carrega a marca do desprezo" ou do "desdém" (VOLTAIRE, M. XXIII, 48-49). Esta tendência invencível de exigir um reconhecimento igualitário da parte do outro revela que a virtude não existe senão como relação e ação. $\mathrm{O}$ bem e o mal não existem para um homem só, e tanto faz que ele seja um asceta ou um destemperado. A interioridade moral desaparece então, pois a virtude consiste totalmente "num comércio de beneficios" entre os homens. Daí porque, a rigor, o adjetivo "virtuoso" não se aplica nem ao caráter, nem a intenção, mas a um trabalho ou um ato que nos coloca em relação com o outro: o próprio Nero pode ser dito virtuoso, enquanto ele realiza boas reformas (VOLTAIRE, M. XX, 573-574 ou VF, 36, 542-543).

Há, portanto, para a lei moral, uma exigência de se efetuar na prática social e a filosofia não escapa a esta exigência. A filosofia deve então se constituir em força ou virtude social, o que requer a tomada de consciência de novas dificuldades. Essas dificuldades explicam as ambiguidades da obra de Voltaire, e notadamente seu emprego do termo "populaça". 
Se a sociedade é de fato pensada por meio da existência de costumes contraditórios, é por que ela se marca essencialmente pelos numerosos males que se opõem à instauração de um comércio de benefícios entre os homens ou à instauração de relações de liberdade e de igualdade efetivas. Mas a sociedade de fato, aquela que o filósofo analisa, exclui uma massa de mendigos sediciosos e, sobretudo, uma populaça rural da qual nada de bom se pode esperar, somente a intolerância e o fanatismo. A França permanece assim um país feudal onde os camponeses enriquecidos se apressam em comprar títulos de nobreza, cargos de magistratura ou de coletor de impostos, de sorte que a sociedade estagna na reprodução perpétua dos privilégios. O acontecimento das Luzes, o desgosto e a saciedade do fanatismo e da miséria da maioria permanece, portanto, provisoriamente, o apanágio de um pequeno número de sábios ou de homens esclarecidos (VOLTAIRE, M. XVIII, 456).

Parece então que Voltaire erra o verdadeiro sentido de uma filosofia social, ao preconizar remédios essencialmente políticos a este estado de coisas. O modelo republicano do Parlamento inglês é assim evocado, já vimos, mas Voltaire pratica também os antigos hábitos das Petições aos Príncipes, por exemplo, quando ele se interessa pelo distrito de Gex, onde ele próprio implantou fábricas que era preciso multiplicar, a fim de garantir as condições de bem-estar elementares aos habitantes que se viam confrontados a uma terra pouco fértil e incapaz de nutri-los. A reforma parece então só poder vir do alto: do Rei ou dos proprietários esclarecidos que criam manufaturas quando o produto da terra é insuficiente. Esses sábios exigem também uma reforma dos impostos, que não devem pesar senão sobre os ricos, contrariamente ao adágio cínico e corrente de seu tempo, de acordo com o qual se deveria deixar o povo na miséria, sem o que ele deixaria de trabalhar (VOLTAIRE, M. XXIX, 306-307). Chega-se assim aparentemente a uma política social que só parece ter por resultado um tipo de "assistência social" avant la lettre, assistência que serviria de fato para proteger a monarquia das sedições e das revoltas possíveis de um povo cujos sofrimentos podem produzir revoluções sanguinárias. Assim, poder-se-ia acusar a prática de Voltaire de ser contraditória, pois nesta perspectiva, ela não aposta mais nas inconsequências dos costumes, mas ela supõe que os costumes do povo são tais que este permanece inconsciente de sua sujeição e, portanto, do evento das Luzes. 
Pode-se responder que a política e seus remédios constituem, no entanto, apenas uma mediação provisória, para uma defesa da igualdade e de uma igualdade amplamente fundada sobre a ideia que o sentido da virtude, como virtude social, está presente em cada um de nós porque se trata de um dom divino indestrutível. Voltaire pensou, com efeito, os limites do político, não somente por meio dos limites da lei, mas como limites intrínsecos. É isto que mostra a ideia segundo a qual a intolerância não é somente o caso de religiões dogmáticas, mas uma questão da política. No curso de sua polêmica com Rousseau, aliás, caricatural e de má fé, por vezes simplista, Voltaire não obstante elabora o conceito de "tolerância política", que exige que os remédios políticos e as formas de governo possam variar de acordo com as "ocasiões", pois a política não é um fim em si, mas o meio de despertar os espíritos e de fazê-los participar da nova liberdade de pensar. O regime inglês de partidos, de representantes, e de seus conflitos incessantes, só é defensável sob a condição de que um partido não imponha um catecismo político tão dogmático e sectário quanto o catecismo religioso. Mas a política em geral dá testemunho de uma tendência à degenerescência, e não podemos depender nem mesmo do governo republicano, no entanto o melhor, para realizar a igualdade social. Pois vemos por toda parte a intriga, a hipocrisia e a ambição tomar o poder e os cargos, a fim de impedir que cada homem possa fazer valer sua «voz para o bem da sociedade". A política de fato não é uma ciência e ninguém pode encontrar "o ponto de apoio" exato que lhe permitiria não se corromper pelos interesses particulares. É preciso por consequência deixar de esperar a salvação pelos princípios do direito político (VOLTAIRE, M. XXIV, 415-419).

O acontecimento das Luzes é então posto em perigo pela necessidade de sempre distinguir a política e o aperfeiçoamento dos costumes sociais: os costumes estão sempre inclinados à desigualdade e à busca do interesse particular, de sorte que há um déspota que dorme em cada um de nós. A partir disso, muitos comentadores concluíram a existência de uma filosofia da infelicidade em um Voltaire que parece subscrever a ideia de uma maldade intrínseca e inextirpável no homem.

É possível, no entanto, oferecer uma outra interpretação desta crítica do político que constitui uma tarefa constante do filósofo. Se os costumes sociais não podem ser mudados por remédios políticos, que são 
necessários, mas insuficientes, e se um povo o mais das vezes ignaro ou mesmo iletrado não ascende à liberdade de pensamento pelo raciocínio filosófico, ora a filosofia deve mudar de natureza. Ela não pode retomar os procedimentos políticos da representação e se fazer a porta-voz dos miseráveis, caso contrário ela própria recairia na constituição de um partido político ou em uma "sociedade de homens de letras" sempre vítima da intriga e da ambição: ela teria mais precisamente a ambição de fazer prevalecer uma aristocracia de gênios, o que Voltaire recusa claramente tanto no domínio teórico quanto no domínio teórico-prático.

$\mathrm{O}$ acontecimento das Luzes ou da liberdade de pensamento exige então garantias contra os perigos do poder político e de suas seitas filosóficas ao inventar uma mediação entre o povo e as verdadeiras Luzes. Mais exatamente a sociedade igualitária e livre se refugia em Voltaire na invenção de uma nova religião não dogmática que é a condição sine qua non de uma transformação dos costumes. Esta religião deve ser capaz de sustentar o laço social entre os homens e de incitá-los, em nome do próprio Deus, à atividade de pensar e agir livremente. Reside aí o sentido fundamental que discernimos de agora em diante naquilo que havíamos chamado de "a antecipação de uma ciência social do religioso"(MARTIN-HAAG, 2002, 171). Da história comparada das religiões, desde aquela dos Chineses àquela dos Quakers, Voltaire tira, com efeito, uma nova ideia de Deus que torna acessível ao povo uma nova ideia da sociedade. Trata-se de inventar uma ideia inteligentemente antropomórfica de Deus, a fim de propor à populaça uma ética que não prescreve normas determinadas, mas a perspectiva da liberdade e da igualdade através do trabalho contínuo. Voltaire nos apresenta assim um teísmo moral em que um Deus bom, mas sem onipotência luta eternamente contra o mal físico e moral sustentando as leis naturais e também a lei moral ou a virtude social inscrita em nós. Todos os homens são então levados a se unir ou a formar uma sociedade imitando ativamente a bondade de Deus. Assim como Deus sustenta a lei moral, o homem deve realizar a lei moral na cidade, resistindo à sujeição, mas também e, sobretudo criando por si próprio o modo de realização social da lei natural e divina. Cabe ao próprio homem, portanto realizar o acontecimento das Luzes ao qual o novo laço religioso fornece uma normatividade, mas sem normas determinadas e fixas. Voltaire considera assim que, contrariamente às leis políticas, a nova ideia de Deus pode ser 
interiorizada e mudar os costumes, canalizando para o seu proveito o amor secular por um Deus de poder e de glória.

É, portanto, fazendo progredir a ideia de Deus, que já mudou bastante entre a maioria, que o filósofo tenta resolver o problema da estagnação dos costumes populares, estagnação que constitui o obstáculo principal à efetivação das Luzes. A nova ideia de Deus fornece assim ao filósofo o ponto de apoio que procuramos em vão na política, e isso para permitir ao povo ousar tomar a palavra, pensar e agir sem outro diretor de consciência que não ele próprio. Assim, cada povo pode se interrogar sobre as condições de uma existência social feliz que permita o livre desenvolvimento de cada um (MARTIN-HAAG, 2002, 163 e 173).

É possível, ao final deste estudo, estimar que o remédio religioso que Voltaire propõe às patologias sociais de seu tempo derroca num idealismo sem eficácia, pois as ideias não movem o mundo. Entretanto, a ideia voluntariamente antropomórfica de Deus que Voltaire propõe à "populaça" não faz apelo ao raciocínio, mas às paixões de justiça e igualdade, por meio de um Deus que ama igualmente todos os homens e que partilha de sua condição. Com efeito, os homens são obrigados, pela história e pela contingência, a sempre lutar contra a inércia do mal e da desordem sobre a Terra.

Do ponto de vista que nos interessa, Voltaire presta testemunho de sua participação na renovação da filosofia como filosofia capaz de refletir sobre sua própria inserção na história e na sociedade. Como Rousseau ${ }^{3}$ e Kant, para além de seus desacordos teóricos, ele pensa uma relação inédita com o presente: o presente das Luzes é concebido duplamente como um evento singular que rompe a história dos costumes, e como uma tarefa a se efetuar tanto para uma sociedade em particular quanto pela sociedade do gênero humano.

\footnotetext{
${ }^{1}$ Ver nossa obra, Voltaire, du cartésianisme aux Lumières, Paris, Vrin, 2002, p. 173.

${ }^{2}$ Des singularités de la nature, Euvres complètes, éd. Louis Moland, Paris, Garnier-Frères, 18771885, t. XVII, p. 190-191. Citaremos os textos de Voltaire nesta edição e quando possível na edição inacabada daVoltaire Foundation, Oxford, 1968-. Essas edições serão daqui em diante e respectivamente abreviadas por $\mathrm{M}$ eVF, seguidas da indicação do tomo e da página.
} 
${ }^{3}$ Sobre esta questão em Rousseau, ver nossa obra, Rousseau ou la conscience social e des Lumières, Paris, Honoré Champion, 2009, em particular p. 90-98.

\section{Referências bibliográficas}

KANT, I. 1991. Qu'est-ce que les Lumières? Paris: GF.

MARTIN-HAAG, E. 2002. Voltaire: du cartésianisme aux Lumières.Vrin, Paris.

VOLTAIRE, M. 1877-1885. Euvres complètes, éd. Louis Moland. Paris: Garnier-Frères.

VOLTAIRE,VF. 1968. Euvres complètes, éd.Voltaire Foundation. Oxford: Oxford University Press. 